\title{
Analysis of Pharmacology Undergraduate Examination Patterns of Medical Universities of South India J Mohan ${ }^{1}$, B N Vallish', M Brahadeesh' ${ }^{2}$, Raj Kishore Mahato ${ }^{3}$ \\ ${ }^{1}$ Associate Professor, ${ }^{2}$ Assistant Professor, ${ }^{3}$ Professor and HOD, Department of Pharmacology, Velammal Medical College Hospital \& Research Institute, Madurai.
}

\begin{abstract}
Introduction: Comprehensive theoretical and practical assessment of pharmacology of $2^{\text {nd }}$ MBBS students during university examinations should ideally be done across the three domains of learning (cognitive, affective, and psychomotor), should be sufficiently interactive, and should cover major subspecialties of pharmacology.

Aims and objectives: To analyse the undergraduate pharmacology examination pattern (theory and practical) of South Indian Universities regarding composition of different domains, extent of examiner-student interaction, and inclusion of questions from different pharmacology subspecialties
\end{abstract}

Materials and methods: Questions asked in theory and practical examination in nine different Universities from Tamil Nadu, Pondicherry, Karnataka, Kerala, and Andhra Pradesh were categorised into (a) domain of learning, (b) interaction present/ absent, and (c) subspecialty, and analysed descriptively.

Results: Cognitive domain dominates over affective and psychomotor domains in both overall examination marks $(81.69 \%, 9.85 \%$, and $8.46 \%$ respectively for the three domains) and in practical examination marks $(87.64 \%, 0.78 \%$, and $11.58 \%$ respectively for the three domains). After excluding viva examination, on an average 56.88\% marks awarded without interaction in practical examination. Questions from clinical pharmacology contributed $59.44 \%$ marks during practical examinations, followed by experimental pharmacology (19.38\%), and spotters (10.91\%). Only two of the nine Universities had incorporated OSPE (objective structured practical examination) exercises in their final practical examination schemes.

Conclusion: There is dominance of cognitive domain in both theory and practical examinations, and student-examiner interaction is inadequate. Examination pattern should be changed to facilitate assessment of psychomotor and affective domains of learning as well, by giving more weightage to formative assessment and OSPE exercises.

Key words: Domains of learning, Bloom's taxonomy, Pharmacology, Practical examination, OSPE

\section{INTRODUCTION:}

$\mathrm{T}$ The three domains of learning - cognitive, affective, and psychomotor - have been widely recognized in the field of education. These domains originally were proposed in 1940s by Benjamin Bloom, whose name is used to refer to this taxonomy. The Bloom's taxonomy of learning domains continues to be a widely used system for imparting medical education and for assessment of medical students across the world. ${ }^{1}$

Pharmacology is a vital subject in medical curriculum that is unique in the allopathic system of medicine. The subject is vast and ever-expanding. 
Knowledge in different sub-specialities of pharmacology such as pharmacovigilance, pharmacogenetics, pharmacoeconomics, clinical pharmacology, experimental pharmacology, and pharmacometrics are essential for the complete understanding of the subject. An in-depth understanding of pharmacology, across all domains of learning, will enable a medical student to use medications rationally and judiciously throughout his/her medical career.

Both learning pharmacology and its assessment should ideally cater to all the three learning domains, namely cognitive (involving knowledge about pharmacology), psychomotor (involving skills involved in drug usage), and affective (involving right attitude in drug usage). Further, a comprehensive assessment of a student's understanding of pharmacological principles can be more accurately made with a direct studentexaminer interaction rather than evaluating written answers. We were curious to know whether the assessment pharmacology understanding of students during the final examinations conducted by different Universities in South India is comprehensive.

The objective of our study was to analyze the pharmacology undergraduate examination patterns of different Universities in Tamil Nadu, Kerala, Karnataka, Andhra Pradesh, and Pondicherry, to specifically estimate:

a. The extent of contribution of different domains of learning for the overall marks in the University pharmacology examination

b. The extent of contribution of different domains of learning in the University practical pharmacology examination c. The extent to which interaction with student is present during the University practical examination

d. The division of the University practical examination topics under various subheadings of pharmacology

\section{MATERIALS AND METHODS:}

Since this study did not involve testing on human or animals, ethics committee clearance was not sought. The practical examination patterns of different universities were obtained either by visiting the university's website, or by contacting a faculty working in a medical college affiliated to the university, during the year 2016. The distribution of marks in the university examination was categorised under four criteria, fulfilling the study's objectives:

\section{A. Distribution of Overall Pharmacology Examination Marks as per Domains of Learning}

\section{Cognitive domain:}

All theory marks and viva marks were categorised under cognitive domain.

\section{Practical Exercises:}

Those practical exercises which involved the performance of a particular skill were classified under psychomotor domain.

\section{Affective domain:}

Since record maintenance reflects the attitude of the student towards the subject, if a university considers record maintenance for the final marks, it was categorised under affective domain. If a University considered extracurricular activities (such as seminars, symposiums, student projects etc) for the final marks, it was categorised under 
affective domain, since scoring good marks in all these activities reflect a positive attitude of the student. Patient communication exercises and exercises concerning rational pharmacotherapy were also considered under affective domain.

Internal Assessment Marks: The percentage distribution of marks under different domains in the external practical examination was extrapolated to split the marks of the practical internal assessment examinations into different domains, under an assumption that the internal assessment practical examination was held in the same way as the external examination.

\section{B. Distribution of University Practical Pharmacology Examination Marks as per Domains of Learning}

\section{Psychomotor Domain:}

Those practical exercises which involved the performance of a particular skill were classified under psychomotor domain

\section{Affective domain:}

If a University has reserved marks for practical records in its final examination and not just a part of internal assessment marks, it was categorised under affective domain. Also, exercises concerning rational pharmacotherapy and patient communication were considered under affective domain.

\section{Cognitive domain:}

All the practical exercises which could not be not classified under psychomotor or affective domains were classified under cognitive domain.

\section{Distribution of University Pharmacology Examination Marks by Interaction of Examiner with Students}

The extent of student interaction was ascertained by speaking with the faculty of medical colleges affiliated to different universities.

\section{Distribution of Pharmacology Examination Marks under Different Subheadings}

\section{Experimental pharmacology:}

All practical exercises relating to performance and/or interpretation of experiments on animals, including chart interpretation

\section{Clinical pharmacology:}

All practical exercises relating to human pharmacological analysis, including prescription writing, prescription audit, pharmacoeconomics, dosage calculation, problem solving exercises, ADRs, toxicology, etc

Pharmacy / chemical pharmacology:

Practical exercises pertaining to dispensing pharmacy, dosage forms, identification of the chemical by doing tests, etc

\section{Spotters:}

Where the University has specifically asked its affiliated colleges to include this type of exercise in the examination

\section{OSPE:}

Where the University has specifically asked its affiliated colleges to include this type of exercise in the examination.

If two or more colleges belonging to the same university gave different type of information, we entered all the data and took an average of all the data for the final calculation. Data were expressed as numbers and percentages; statistical analysis was not done for the data since the study was of a descriptive nature. 


\section{RESULTS:}

A total of 20 medical colleges affiliated to nine Universities in the states of Tamil Nadu (five universities), Karnataka, Pondicherry, Andhra Pradesh, and Kerala (one university each) were included in this study. Out of the nine universities, three were deemed medical universities with multiple medical colleges affiliated to them, one was a deemed to be university with only one medical college under it, Four were Health Sciences Universities of their respective states, and one was a general University (not restricting to Health Sciences).

\section{A. Distribution of Overall Pharmacology Examination Marks as per Domains of Learning}

All the nine universities under consideration put the maximum emphasis on the cognitive domain when compared to the other two domains. On an average, the distribution of marks under the cognitive domain was $81.69 \%$, followed by affective domain at $9.85 \%$ and the psychomotor domain at $8.46 \%$ respectively. Notably, four out of the nine universities had zero contribution from psychomotor domain. Figure 1 summarises the marks distribution under different domains.

\section{Figure 1 : Distribution of pharmacology} examination marks under different domains

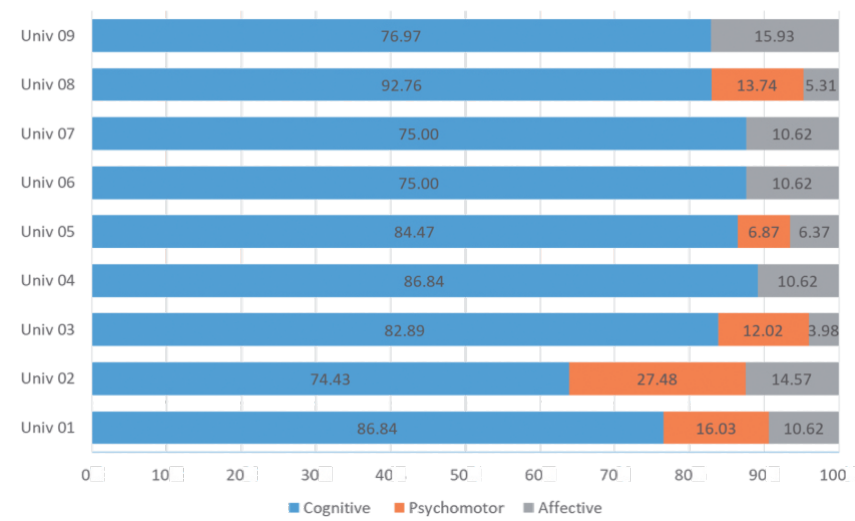

\section{B. Distribution of University Practical Pharmacology Examination Marks as per Domains of Learning}

The emphasis on cognitive domain continued even during the practical examination in all the nine universities under consideration. On an average, the distribution of marks under the cognitive domain was $87.64 \%$, followed by psychomotor domain at $11.58 \%$ and affective domain at $0.78 \%$. Only one of the nine universities tested the affective domain during practical examination (in the form of patient communication exercises). Importantly, four universities had zero contribution from the psychomotor domain, despite the heading being 'practical' examination. Figure 2 summarises the marks distribution under different domains.

Figure 2 : Distribution of pharmacology practical examination marks under different domains

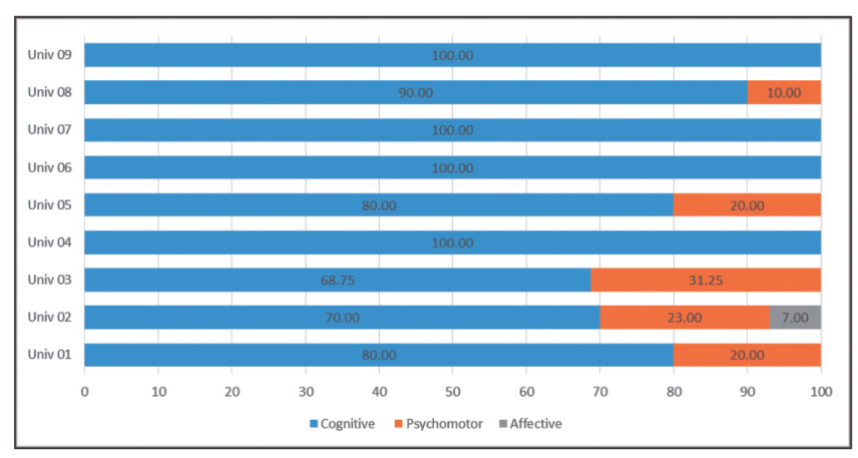

C. Distribution of University Pharmacology Examination Marks by Interaction of Examiner with Students

On an average, $56.88 \%$ of marks were awarded in practical examination without direct interaction with students. Out of the nine universities, only two universities had more proportion of questions 
which involved student interaction with the examiners than those which did not. Figure 3 summarises the distribution of marks based on the level of interaction between students and examiners.

Figure 3 : Distribution of pharmacology practical examination marks based on presence or absence of interaction between student and

\section{examiner}

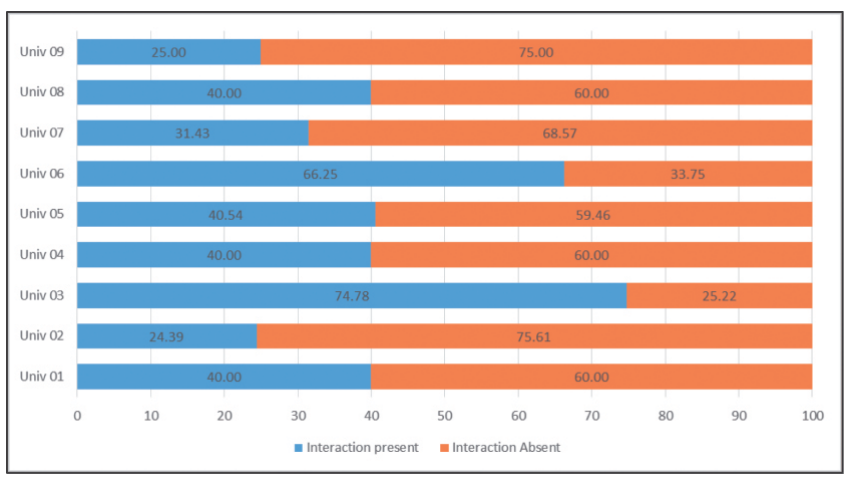

\section{Distribution of Pharmacology Examination}

\section{Marks under Different Subheadings}

On an average, $59.44 \%$ of questions came from topics under clinical pharmacology, and all universities had questions from this topic. Experimental pharmacology questions averaged $19.38 \%$ of questions, and barring two universities, all universities had questions from this topic. Likewise, spotters was also a question in all the universities except two, and on an average contributed to $10.91 \%$ of marks. Only one university had questions from clinical pharmacy/ chemical pharmacology, and only two universities had incorporated OSPE under their examination scheme. The distribution of marks between the different subheadings was not constant or uniform between the Universities. Figure 4 summarises the marks distribution based on the subheadings.
Figure-4: Distribution of pharmacology practical examination marks under different subheadings

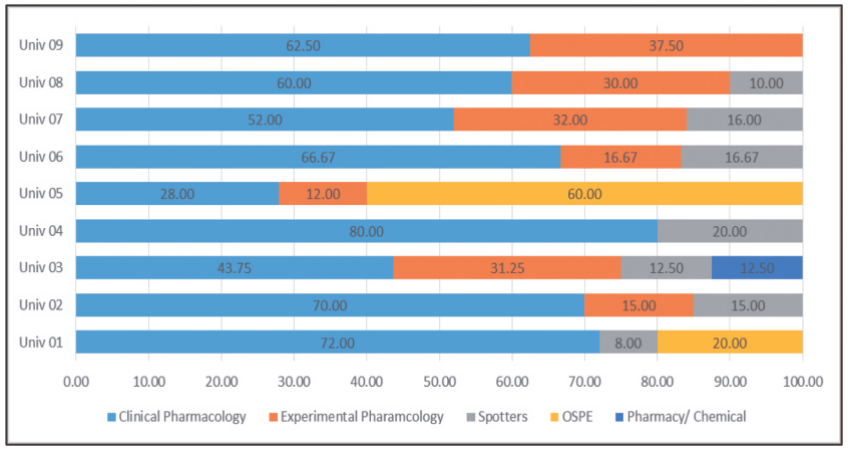

\section{DISCUSSION:}

Pharmacology is an ever-changing subject. Undergraduate pharmacology teaching has undergone significant changes in the past. The changes that have happened in the field of pharmacology have had a greater impact on conducting of pharmacology practicals. In the past, pharmacology practicals consisted of experimental pharmacology involving small animals and amphibians, and dispensing pharmacy exercises, both of which required performance of skilful activities on the part of the student. With time, for various reasons, both of these exercises were removed from the undergraduate practical pharmacology teaching programmes in most of the Health Universities in India. ${ }^{2}$ This has led to the present state where maximum emphasis is given to exercises involving clinical pharmacology while conducting and assessing practical aspects of pharmacology. This change correctly reflects the current pattern of emphasis in the subject where clinical pharmacology is given more importance; however, most of the clinical pharmacology exercises are theoretical in nature and involve very minimum psychomotor and affective domains. The increasingly theoretical nature of pharmacology practicals has resulted in second year medical students terming the pharmacology practicals as being the 'most boring and least useful' among all 
the second year practical exercises, despite also considering pharmacology to be the most important second year subject. ${ }^{3}$ Thus, it is very much apparent that there is a desperate need to make practical pharmacology more interesting and involving more active participation from the students.

The direction of medical education in India is driven primarily by the guidelines and syllabi prescribed by the medical universities. Even though medical teaching should ideally be 'knowledge-oriented', in our experience, we have seen that the medical teaching is gradually becoming 'exam-oriented'. This means that, if a change is required in the way a subject is taught, it should primarily reflect in the way the questions are framed in the examinations. Thus, our objective behind performing this analysis was to see how different medical universities conduct examinations in pharmacology. We looked at this question from three different viewpoints: (a) how much contribution is coming from different domains of learning; (b) how much emphasis is being given to interaction with students, and; (c) are the practical exercises coming from different sub-specialties of pharmacology, thus making the assessment a holistic one.

Our intention while performing this analysis was to explore whether the assessment methodologies followed by different Universities are comprehensively evaluating the pharmacology learning of the students across all domains and to what extent actual student-examiner interaction is present. Our objective was not to highlight the deficiency in the assessment method of any particular University, and for this reason, we have not disclosed the names of the individual Universities. This study has highlighted the present situation of non-uniformity of assessment during final pharmacology examination conducted by different Universities in South India.
While all the nine Universities in our study assessed the learning in the cognitive domain, the other two domains (psychomotor and affective) were assessed to a very small extent. A predominance of cognitive domain is understandable in the written (theory) examination and viva-voce, but the practical exercises should be designed and assessed in such a way that the learning of the student across all the three domains is equally assessed. Contrary to this expectation, we found in our study that in all the nine Universities, even during practical pharmacology assessment the cognitive domain is given more importance with psychomotor skill assessment contributing to only $11.58 \%$ marks.

Only one out of the nine Universities concerned had assessment involving affective domain in the practical examination; this was a patient communication exercise, and contributed 7 out of 100 marks in the practical examination. Further, the amount of interaction between the examiners and the examinees during practical examination, excluding viva, is a mere $43.12 \%$. On a more encouraging note, we observed that the practical exercises across different Universities focus mostly on clinical pharmacology with lesser emphasis on experimental pharmacology and clinical pharmacy / chemical pharmacology, which is in accordance to the current trend in medical pharmacology. Only two out of the nine Universities considered in the study had incorporated the OSPE exercises.

The disproportionately high importance to cognitive domain at the expense of psychomotor and affective domains in the practical examination, and the fact that the extent of interaction between examiners and students during practical examination is under $50 \%$ are areas of major concern. Even though the knowledge is the prerequisite for skill and behavioural changes, 
ignoring of psychomotor and affective domains of learning is counterproductive. This has been the case in the medical education in India, as acknowledged by past literature. ${ }^{4}$ Thus, the assessment techniques should be modified in such a way that affective and psychomotor domains supplement the already predominant cognitive domain, and the amount of interaction between students and examiners is increased during both formative and summative assessments.

There are two possible methods by which such changes can be brought about in pharmacology practical assessment: (a) the weightage given to internal assessment marks should be increased, and seminars, projects etc should be included under internal assessment, and, (b) more weightage should be given to OSPE exercises.

Since medical students in India spent 3 semesters (18 months) in $2^{\text {nd }}$ MBBS, formative assessment done throughout the $2^{\text {nd }}$ MBBS should be an essential part of student assessment. Formative assessment assesses students' achievements, and also enables students to identify the areas in which they are facing difficulty and initiate corrective measures. Formative assessment done in optimum frequency with immediate feedback can help in the overall development of the student. ${ }^{5}$ The inclusion of headings like seminars, student projects, quiz, participation in research, group discussions, problem-based learning and case-based learning under formative assessment not only makes the practical sessions interesting and lively, but also contributes to the affective domain (and to a small extent, psychomotor domain) of learning and assessment. In fact, the internal assessment may be modified to include very minimum theoretical questions (contributing to cognitive domain) and mostly practical questions (contributing to psychomotor and affective domains, and also involving more interaction).
However, since the internal assessment marks contributes to a very small extent to the final marks, students generally give less importance these 'cocurricular activities'. In fact, many students study only before the examinations. ${ }^{2}$ If internal assessment is given more importance, then students will be made responsible to study from day 1. In fact, premier institutions like AIIMS Delhi allocate $50 \%$ of the total marks to internal assessment. ${ }^{6}$ This modification should be considered by all health Universities under all subjects in general, and Pharmacology in particular.

The second suggestion concerns OSPE exercises. These exercises were derived from objective structured clinical examination (OSCE), which was originally conceptualized in 1975 . $^{7}$ By the OSPE method, the competency of the examinees can be assessed objectively through direct observation. By incorporating OSPE in Pharmacology, the assessment can be made more objective, a wide area of knowledge and skills can be assessed in a short time with minimum variability, and affective and psychomotor domains also can be assessed, in addition to the cognitive domain. ${ }^{8}$ The incorporation of OSPE exercises in the pharmacology practical examination scheme by Universities will make the student assessment more comprehensive, and will also break the monotony of the assessment. At least $50 \%$ of marks in the practical examination should be earmarked for OSPE exercises.

Examples for OSPE exercises in pharmacology include demonstration of injection techniques in mannequins, interpretation of pharmacodynamic and pharmacokinetic charts, interpretation of animal experiment results, filling up of ADR forms, criticising on the rationality (or its lack) in fixed drug concentrations, patient communication skills, rational pharmacotherapeutic exercises, etc. 
The limitations of the present study includes small sample size and non-usage of statistics for analysing the data. However, by this study, we have a general idea as to how the cognitive domain is being tested at the expense of affective and psychomotor domains even in the practical examinations. Further studies in this direction including more Universities and more subjects may further corroborate our findings.

\section{CONCLUSION:}

To conclude, we found in our study that most Medical Universities in South India give more importance to cognitive domain of learning while ignoring affective and psychomotor domains under assessment of undergraduate pharmacology, and this trend is seen even during practical examination. Interaction between students and examiners is less than $50 \%$, and clinical pharmacological exercises dominate over other sub-specialities of pharmacology. In order to enhance assessment of psychomotor and affective domains, we suggest enhancing weightage given to (a) internal assessment marks and to include student seminars and projects as components for internal assessments, and (b) OSPE exercises during practical examination. By these steps, we can go one further step in making the students realise that good knowledge in pharmacology is the bedrock for rational pharmacotherapeutics, and thus contributing to the creation of responsible doctors for the future generation.

SOURCES OF FUNDING: Self-funded

CONFLICTS OF INTEREST: None to declare

\section{REFERENCES:}

1. Yanofsky SD, Nyquist JG. Using the affective domain to enhance teaching of the ACGME competencies in anesthesiology training. J Educ Perioper Med 2010; 12: E055.

2. Haranath PSRK. Medical curriculum and pharmacology: An appraisal. Indian J Pharmacol 2016; 48 (Suppl 1): S10-S13.

3. Naeem SS, Rizvi W, Kumar A. Revisiting undergraduate practical pharmacology. J Pharmacol Pharmacother 2012; 3(1): 76-9.

4. Gopalakrishnan S, Kumar PG. Community medicine teaching and evaluation: scope of betterment. J Clin Diagn Res. 2015 Jan; 9(1): JE01-5.

5. Jain V, Agrawal V, Biswas S. Use of formative assessment as an educational tool. J Ayub Med Coll Abbottabad. 2012 Jul-Dec; 24 (3-4) : 6870 .

6. All India Institute of Medical Sciences, New Delhi. Syllabus for MBBS. [online] [cited 27 Oct 2017]. Available at: URL: http://www.aiims.edu/aiims/academic/aiimssyllabus/Syllabus\%20-\%20MBBS.pdf

7. Harden RM, Stevenson M, Downie WW, Wilson GM. Assessment of clinical competence using objective structured examination. Br Med J. 1975 Feb 22 ; 1(5955): 447-51.

8. Vishwakarma K, Sharma M, Matreja PS, Giri.V.P. Introducing objective structured practical examination as a method of learning and evaluation for undergraduate pharmacology. Indian J Pharmacol. 2016; 48 (Suppl 1) : S47-S51.

Received on 04/11/2017 Revised on 13/12/2017 Accepted on 18/12/2017 